\title{
Surveillance of Antibiotic Resistant Staphylococcus aureus in Agricultural Production Chain of Mongolia
}

\author{
Tumuruu Gantsetseg ${ }^{1}$, Jargalsaikhan Enkhtuya ${ }^{1}$, Tundev Odgerel $^{2}$, Ochirpurev Ariuntuya ${ }^{3}$ and Sodnom \\ Lkhagvasuren $^{1}$ \\ 1. Institute of Veterinary Medicine, Ulaanbaatar 17024, P.O. Box 53/24, Mongolia \\ 2. National Center for Communicable Disease, Ulaanbaatar 17024, P.O. Box 53/24, Mongolia \\ 3. WHO Representative Office in Mongolia, Ulaanbaatar P.O. Box 46/78, Mongolia
}

\begin{abstract}
Monitoring of food borne pathogens in food is the primary tool for the implementation of food safety systems. It is necessary to monitor the prevalence of food borne pathogens for effective food safety planning and targeted interventions. Staphylococcus aureus is considered as the third largest cause of food related illness in worldwide. The present study aimed at surveillance of $S$. aureus contamination of meat on meat supply chain stages, which is a common benchmark of meat market in Mongolia, and characterization of isolated and collected strains from other agricultural sources. The cultural and polymerase chain reaction (PCR) methods were used for isolation, identification and characterization of S. aureus. In 216 cultures of S. aureus among 634 Staphylococci isolates obtained from different sources throughout the agricultural production chain in this study, common gene for S. aureus (98.74\%), and nuc (97.47\%), mecA (44.12\%), msrA (9.66\%), gyrA (32.77\%) and ermC (29.41\%) genes were identified. As seen in the surveillance result, the prevalence of methicillin-resistance $S$. aureus (MRSA) is $44 \%$ among $S$. aureus isolates from agricultural production chain. Confirmed cases of food-borne infections and intoxications caused by $S$. aureus should be considered as one of mean criteria of food safety issues in Mongolia, and special attentions should be paid on antibiotic resistant bacteria, such as S. aureus.
\end{abstract}

Key words: Meat supply chain, mecA positive Staphylococcus aureus, polymerase chain reaction.

\section{Introduction}

Staphylococcus aureus is a bacterium, which causes food-borne and fomite-borne infections and intoxications [1]. Among healthy humans, $30 \%$ carry S. aureus, which causes various infections, intoxications, postsurgical infections, pustule and sepsis [2]. Virulence factors of S. aureus include: (1) surface proteins that promote colonization of host tissues; (2) invasins (leukocidin, kinases, hyaluronidase); (3) surface factors (capsule, protein A); (4) biochemical properties (carotenoids, catalase production); (5) immunological disguises (protein A, coagulase); (6) membrane-damaging toxins (hemolysins, leukotoxin, leukocidin); (7) exotoxins (SEA-G, TSST, ET); (8) inherent and acquired resistance to antimicrobial agents [3].

Corresponding author: Sodnom Lkhagvasuren, associate professor, research field: food safety.
S. aureus is considered as the third largest cause of food related illness in worldwide [4]. Monitoring the presence of food borne pathogens in food is the primary tool for the implementation of food safety systems. It is necessary to monitor the prevalence of food borne pathogens for effective food safety planning and targeted interventions [5]. Methicillin-resistant $S$. aureus (MRSA) that is resistant to virtually all $\beta$-lactam antibiotics is mediated by the chromosomally located mecA gene [6].

Livestock constitutes a potential reservoir of MRSA isolates belonging to a recently derived lineage within clonal complex 398 (MRSA CC398-IIa). Since its discovery in the early 2000s, this lineage has become a major cause of human disease in Europe, posing a serious public health challenge in countries with intensive livestock production. Various studies suggest that environmental contamination of air and 
contacted surfaces may also contribute to MRSA CC398 transmission [7-10]. Moreover, MRSA CC398 is a relatively common contaminant of retail meat in Europe, and food-borne transmission has been hypothesized as a possible source of infections in people with no livestock contact. However, epidemiological data suggest that food-borne transmission is rare [11].

Results of the studies in last years demonstrate that the use of antibiotics is now out of control and antibiotics resistance of bacteria is broadening in Mongolia [12]. Among cases of food-borne infections and intoxications in Mongolia, it caused by S. aureus is not rare. For instance, intoxications occurrence increased two times during last two years according to the Bacteriological Laboratory of National Center for Communicable Disease (NCCD), and a total of 216 coagulase-positive Staphylococci cultures were determined, as all cultures were sensitive to cefazolin and $79 \%$ to ciprofloxacin, but $60 \%$ were resistant to penicillin and ampicillin in 2012. Also an outbreak among soldiers in the Army Unit 167 in Umnugovi aimag was caused by $S$. aureus and $S$. aureus were detected in textbooks of school children in Orkhon aimag [13].

With development of molecular techniques, polymerase chain reaction (PCR) has become recently an important tool for detecting pathogenic microorganisms in food products by replacing the time-consuming culture-based classical techniques [14]. It is rapid, easy to handle, sensitive and specific, and constitutes very valuable tools for microbiological applications.

Therefore, it has been essentially important to detect bacteria resistance to antibiotics, conduct surveillance of them, make risk assessments, improve diagnostic capacity and take control on veterinary drug use. Thus, the present study aimed to conduct surveillance of $S$. aureus, detect its virulence and antibiotic resistance and improve their diagnostic technology and proficiency testing.

\section{Materials and Methods}

\subsection{Sampling and Strains Collection}

Isolates, cultures and strains from six sources were used for studying antibiotic resistance of $S$. aureus as shown in Table 1. The strains were collected from laboratories, including NCCD Bacteriological Laboratory, State Central Veterinary Laboratory (SCVL), Veterinary Laboratory of Implementing Agency of the City Mayor (VLUC), National Reference Laboratory of Food Safety of General Agency for Specialized Inspection (NRLFS-GASI), Food Safety and Hygiene Laboratory of Institute of Veterinary Medicine (FSHL-IVM) and Laboratory of Infection Diseases and Immunology (LIDI-IVM) Mongolia.

\subsection{Isolation and Identification by Cultural Methods}

Specimen from animal products and fomites were planted on both nutrient and nutrient agar, a total of $225 \mathrm{~mL}$ of tryptic soya broth (TSB; Oxoid, Basingstoke, Hampshire, UK) containing $10 \% \mathrm{NaCl}$ was added to $25 \mathrm{~g}$ of aseptically ground sample in a stomacher bag. Bags were stomached using a Stomacher 400 circulator (Seward, Inc., London, UK) at $230 \mathrm{rpm}$ for $2 \mathrm{~min}$, then incubated at $35^{\circ} \mathrm{C}$ for $24 \mathrm{~h}$ [15]. Then, smear was prepared and stained by Gram's method and Gram positive clustered cocci were selected. Colonies were selected based on whether the cocci cause beta hemolysis on blood agar and form black colonies on Baird Parker selective agar. In order to differentiate staphylococci from other cocci, catalase test was used, while coagulase test was used to identify S. aureus from other Staphylococci [15].

\subsection{Biochemical Test}

For identification of Staphylococci by biochemical characteristics, API Staph test kit (BioMerieux) was used as described in the manufacturers instruction [16]. Briefly, the following steps and procedures were used. The first step in this procedure is to make a saline suspension of the organism from an isolated colony. A 
Table 1 Sampling and collection strains.

\begin{tabular}{|c|c|c|c|c|c|c|c|c|c|c|c|c|c|c|c|c|c|c|}
\hline \multirow{3}{*}{$\begin{array}{l}\text { Collection } \\
\text { Sources }\end{array}$} & \multicolumn{18}{|c|}{ Sampling from food chains } \\
\hline & \multicolumn{4}{|c|}{ From slaughtering house } & \multicolumn{3}{|c|}{ From food market } & \multicolumn{4}{|c|}{ From beef production } & \multicolumn{4}{|c|}{ From broiler } & \multirow{2}{*}{$\begin{array}{l}\text { From } \\
\text { horse }\end{array}$} & \multirow{2}{*}{$\begin{array}{l}\text { From } \\
\text { patients } \\
\text { Nasa } \\
\text { swabs } \\
\end{array}$} & \multirow[b]{2}{*}{-Total } \\
\hline & Animals & $\begin{array}{l}\text { Meat } \\
\text { samples }\end{array}$ & Swabs & Carriers & $\begin{array}{l}\text { Meat } \\
\text { samples }\end{array}$ & Swabs & Carriers & Feed & $\begin{array}{l}\text { Slaughter } \\
\text { animals }\end{array}$ & $\begin{array}{l}\text { Processing } \\
\text { plant }\end{array}$ & Retail & Broilers & Slaughter & $\begin{array}{l}\text { Processing } \\
\text { plant }\end{array}$ & Retail & & & \\
\hline $\begin{array}{l}\text { No. of } \\
\text { samples }\end{array}$ & 52 & 52 & 52 & 52 & 104 & 102 & 87 & - & - & - & - & - & - & - & - & 360 & - & 861 \\
\hline $\begin{array}{l}\text { No. of } \\
\text { strains }\end{array}$ & 2 & 3 & 5 & 2 & 15 & 31 & 3 & 7 & 8 & 6 & 9 & 23 & 22 & 18 & 13 & 13 & 36 & 216 \\
\hline
\end{tabular}

Cultures taken from laboratories, such as NCCD Bacteriological Laboratory, SCVL, VLUC, NRLFS, FSHL-IVM and LIDI-IVM, and samples collected for last 3-4 years in these laboratories from the above mentioned sources.

-: unknown numbers of samples.

Table 2 Primers used for the study.

\begin{tabular}{|c|c|c|c|c|c|}
\hline No. & Name of gene & Target sequences & PCR primer' sequences (51 to 31 ) & Product size $(\mathrm{bp})$ & Reference \\
\hline 1 & Common & S. aureus & $\begin{array}{l}\text { AAT CTT TGT CGG TAC ACG ATA TTC TTC ACG } \\
\text { CGT AAT GAG ATT TCA GTA GAT AAT ACA ACA }\end{array}$ & 108 & {$[17]$} \\
\hline 2 & ermC & Erythromycin resistance of S. aureus & $\begin{array}{l}\text { CTT GTT GAT CAC GAT AAT TTC CC } \\
\text { ATC TTT TAG CAA ACC CGT ATT C }\end{array}$ & 190 & {$[18]$} \\
\hline 3 & $m s r A$ & Macrolide resistance efflux of $S$. aureus & $\begin{array}{l}\text { TCC AAT CAT TGC ACA AAA TC } \\
\text { AAT TCC CTC TAT TTG GTG GT }\end{array}$ & 163 & [19] \\
\hline 4 & mecA & Methicillin resistance of $S$. aureus & $\begin{array}{l}\text { AAC AGG TGA ATT ATT AGC ACT TGT AAG } \\
\text { AAT TCC CTC TAT TTG GTG GT }\end{array}$ & 174 & {$[20]$} \\
\hline 5 & nuс & Thermostable nuclease of S. aureus & $\begin{array}{l}\text { GCGATTGATGGTGATACGGTT } \\
\text { CAAGCCTTGACGAACTAAAGC }\end{array}$ & 276 & {$[21]$} \\
\hline 6 & VSMec & Penicillin binding protein of $S$. aureus & $\begin{array}{l}\text { TGG CTA TCG TGT CAC AAT CG } \\
\text { CTG GAA CTT GTT GAG CAG AG }\end{array}$ & 310 & {$[22]$} \\
\hline
\end{tabular}


staph strip is then placed in a tray that has a small amount of water added to it to provide humidity during incubation. Next, a sterile pipette is used to dispense 2-3 drops of the bacterial suspension to each micro cupule. The inoculated tray is covered and incubated aerobically for $18-24 \mathrm{~h}$ at $35-37^{\circ} \mathrm{C}$. Finally, a seven-digit profile number is obtained and used to identify the bacteria.

\subsection{Antibiotic Resistance Test}

Antibiotic resistance and susceptibility of $216 \mathrm{~S}$. aureus cultures, isolated and collected during the study, were checked by use of disc diffusion test [23], DNA of antibiotic resistant strains was extracted and the gene for antibiotics resistance was amplified by PCR using primer shown in Table 2.

\subsubsection{Disk Diffusion Test (Kirby-Bauer Method)}

The test is performed by applying a bacterial inoculation of approximately $1 \mathrm{CFU} / \mathrm{mL}$ to the surface diameter Mueller-Hinton agar plate. Commercially-prepared by Biolab, Zrt and HiMedia fixed concentration, antibiotic disks are placed on the inoculated agar surface. Plates are incubated for 16-24 $\mathrm{h}$ at $35^{\circ} \mathrm{C}$ prior to determination of results. The zones of growth inhibition around each of the antibiotic disks are measured to the nearest millimeter. The diameter of the zone is related to the susceptibility of the isolate and to the diffusion rate of the drug through the agar medium [24].

\subsubsection{DNA Extraction and Purification}

To extract bacterial DNA, $400 \mu \mathrm{L}$ isolate was placed into microtube and centrifuged at 1,000 rpm for $30 \mathrm{~min}$. Then, $200 \mu \mathrm{L}$ of pellet was pipetted into new microtube and centrifuged at $8,000 \mathrm{rpm}$ for 15 min. Supernatant was removed and $200 \mu \mathrm{L}$ distilled water was added into the precipitate, followed by mixing in vortex. Then, the mixture was placed in boiling water for $15 \mathrm{~min}$ and template was prepared by centrifuging at $1,0000 \mathrm{rpm}$ for $10 \mathrm{~min}$.

DNA was extracted from blood and nasal swabs using the QIAamp DNA mini kit from Qiagen. The
QIAamp DNA mini kit was used for the protocol of commercial guideline. To isolate DNA from meat, phenol-chloroform extraction method was used. Yield and purity of isolated DNA were measured by spectrophotometer at $260 \mathrm{~nm}$ and $280 \mathrm{~nm}$ wavelength and the purity ranged between 1.72 to 1.94 .

\subsubsection{PCR Method}

For the surveillance of genes of $S$. aureus, which is resistant to both $\beta$-lactam and non $\beta$-lactam antibiotics, including oxacillin, methiciliin and erythromycin, the following primers shown in Table 2 and both of PCR and multiplex PCR methods for surveillance of antibiotics resistant genes were used [25].

\subsubsection{Reaction Mixture}

Total of $25 \mu \mathrm{L}$ of mixture, containing $2.5 \mu \mathrm{L} 10 \times$ PCR buffer, $2 \mu \mathrm{L}$ dNTP (GeneAmp, UK) (each 2.5 $\mathrm{mM}), 2 \mu \mathrm{L}$ template, $1.5 \mu \mathrm{L} \mathrm{MgCl}_{2}, 1 \mu \mathrm{L}$ of each of primers 1 and $2,0.175 \mu \mathrm{L}$ of 5 unit $/ \mu \mathrm{M}$ taq DNA polymerase (TaKaRa, Japan), and $14.815 \mu \mathrm{L}$ $\mathrm{ddH}_{2} \mathrm{O} / \mathrm{DW}$, was taken. In using multiplex PCR, subtractions form water equal to amounts of primer and $\mathrm{MgCl}_{2}$ were estimated and each primer was taken in dependent on concentrations [25].

\subsubsection{Amplification}

In total of 35 cycles, there were such steps as initialization at $95{ }^{\circ} \mathrm{C}$ for $7 \mathrm{~min}$, denaturation at $94{ }^{\circ} \mathrm{C}$ for $1 \mathrm{~min}$, annealing at $55^{\circ} \mathrm{C}$ for $1 \mathrm{~min}$, elongation at $72{ }^{\circ} \mathrm{C}$ for $1 \mathrm{~min}$ and final elongation at $72{ }^{\circ} \mathrm{C}$ for 7 min, which was $10 \mathrm{~min}$ for multiplex PCR [25].

\subsubsection{Gel Electrophoresis}

Mixture of $8 \mu \mathrm{L}$ PCR product and $2 \mu \mathrm{L}$ loading buffer was loaded in wells on the gel, and run in $1.5 \%-2 \%$ agarose gel depending on its DNA length. The gel was stained by ethidium bromide for $15 \mathrm{~min}$ and DNA fragments were visualized on transilluminator at $320 \mathrm{~nm}$ wavelength.

\section{Results and Discussion}

\subsection{Prevalence and Identification of S. aureus}

Of 861 samples taken from meat production and distribution chain, coagulase-positive Staphylococcus 
samples represent $10 \%$ by microbiological method, whilst $12 \%$ were coagulase positive Staphylococcus by PCR method (Table 3 ). In these positive samples, $S$. aureus was detected in $3.8 \%$ of animal samples, $5.8 \%$ of meat samples, $9.6 \%$ of environmental swabs and $3.8 \%$ of patients (Table 3, Fig. 1).

For samples taken from food markets, S. aureus was detected in $14.42 \%$ of meat, $3.4 \%$ in carriers and $30.4 \%$ in fomite surface swabs (Fig. 2). Of 156 strains and cultures identified by laboratory examinations in the last three years, $83.7 \%$ were positive for mecA $S$. aureus. Furthermore, $3.6 \%$ of $S$. aureus identified from 360 horse samples (nasal swab and blood) of Selenge, Darkhan, Orkhon-Uul and Bulgan provinces were positive for mecA S. aureus (Table 4).

\subsection{Result of API Staph Test}

Isolates from fomites and animal products accounted for $61.3 \%$ and $28.7 \%$, respectively, in total isolates and serotyping of staphylococci by API test. When serotype of 634 cultures of Staphylococcus by their biochemistry and enzyme activity identified, there were S. aureus (35.3\%), S. xylosus (29.4\%), S. hominis $(17.6 \%)$ and S. saprophyticus (8.8\%) (Fig. 3). Results of the study demonstrated that portion of $S$. aureus, which is the cause of infection and intoxication, was greater than other types and $S$. aureus is seen to be indicator of fomite borne infection (Fig. 4).

Table 3 Results of isolation and identification of $S$. aureus from meat chain.

\begin{tabular}{|c|c|c|c|c|c|}
\hline \multirow{2}{*}{ Collection } & \multirow{2}{*}{ Kind } & \multicolumn{2}{|c|}{ No. of isolation and identification of S. aureus } & \multirow{2}{*}{-Sub-total } & \multirow{2}{*}{ Total } \\
\hline & & Slaughtering house & Food markets & & \\
\hline \multirow{4}{*}{ Sample } & Animals & 52 & 0 & 52 & \multirow{4}{*}{501} \\
\hline & Meat & 52 & 104 & 156 & \\
\hline & Swabs & 52 & 102 & 154 & \\
\hline & Carriers & 52 & 87 & 139 & \\
\hline \multicolumn{6}{|l|}{ Isolates } \\
\hline \multirow{4}{*}{ by $\mathrm{CM}$} & Animals & 2 & 0 & 2 & \multirow{4}{*}{50} \\
\hline & Meat & 2 & 12 & 14 & \\
\hline & Swabs & 4 & 28 & 32 & \\
\hline & Carrier & 1 & 1 & 2 & \\
\hline \multirow{4}{*}{ by PCR } & Animals & 2 & 0 & 2 & \multirow{4}{*}{61} \\
\hline & Meat & 3 & 15 & 18 & \\
\hline & Swabs & 5 & 31 & 36 & \\
\hline & Carrier & 2 & 3 & 5 & \\
\hline
\end{tabular}

CM: cultural method.

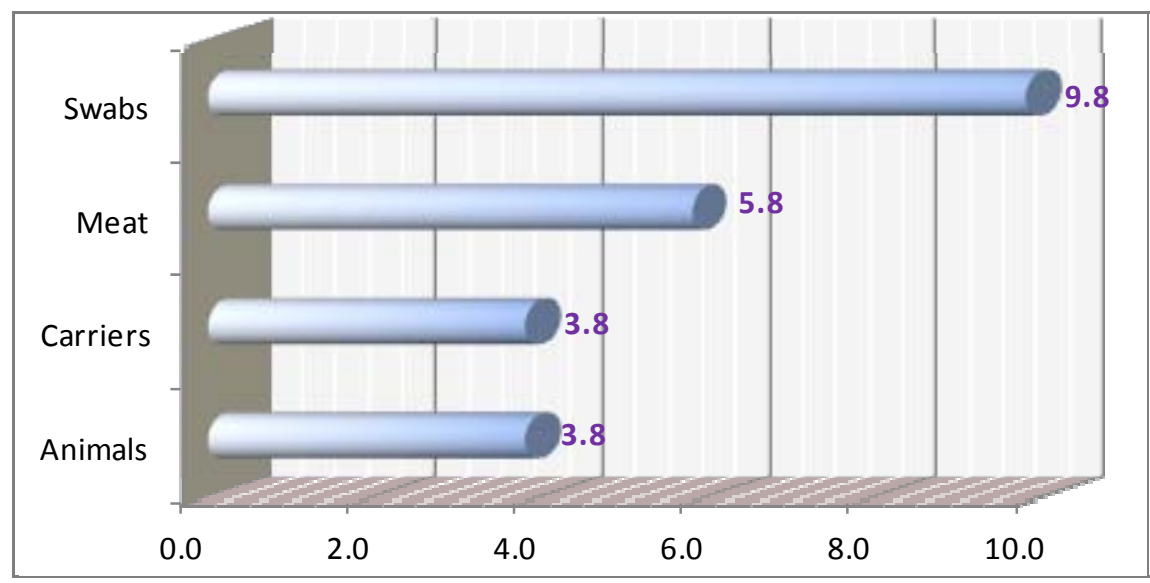

Fig. 1 Percentage of $S$. aureus of total samples on slaughter house. 


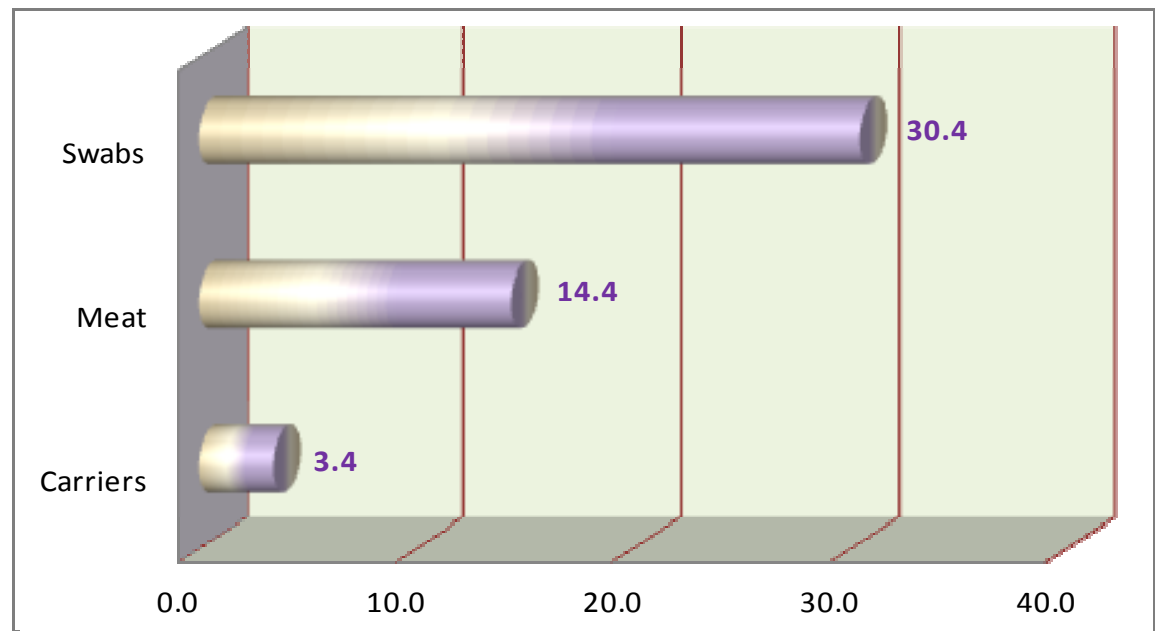

Fig. 2 Percentage of $S$. aureus of total samples on slaughter house.

Table 4 Strains collected from laboratories and $m e c A$ positive results.

\begin{tabular}{llllll}
\hline No. & Host & Sources & Laboratories & Cultures and strains & mecA positive S. aureus \\
\hline \multirow{4}{*}{1} & Feed & SCVL & 7 & 6 \\
& Cattle & Slaughtering animal & SCVL & 8 & 5 \\
& & Processing plant & SCVL/FSHL & 6 & 6 \\
& Retail & SCVL/FSHL & 9 & 8 \\
\hline \multirow{4}{*}{ Broiler } & Broilers & VLCC \& FSHL & 23 & 19 \\
& & Slaughtering & VLCC \& FSHL & 22 & 16 \\
& Processing & VLCC \& FSHL & 18 & 13 \\
\hline 3 & Retail & VLCC \& FSHL & 13 & 9 \\
\hline 4 & Horse samples (360) & & IVM-LIDI & 13 & 13 \\
\hline \multicolumn{2}{l}{ Total cultures and strains from labs } & NCCD & 37 & 36 \\
\hline
\end{tabular}

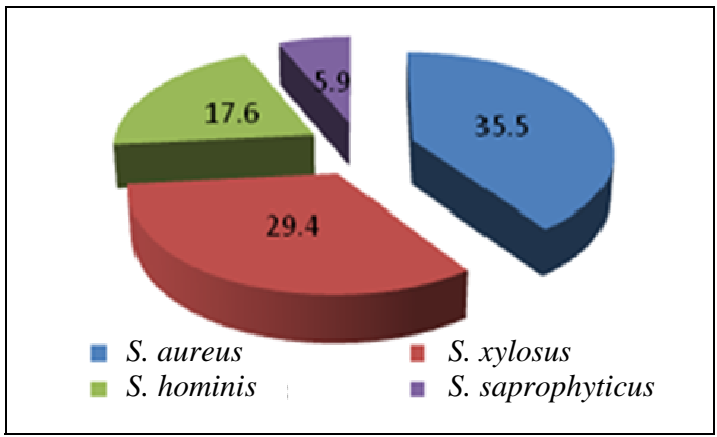

Fig. 3 Serotypes of Staphylococci.

\subsection{Result of Disk Diffusion Test}

Result of antibiotic disk diffusion test showed that of 216 isolates of aureus from meat and related environment, $72.7 \%$ are resistant to amoxycillin (Am10), $63.6 \%$ to penicillin (P10), 18.8\% to cefazolin (CZ30), 9.1\% to nitrofurantoin (F/M), 89.8\% to ampicilin (A10), 89.9\% to oxacillin (OX10), 36.4\% to doxycyclin (D30), 9.1\% to erythromycin (E15) and $45.5 \%$ to chloramphenicol (C30) and all were sensitive to gentamicin (GM 10) (Figs. 5 and 6).

3.4 Result of PCR Analysis on Virulence and Antibiotic Resistance Genes of S. aureus

Molecular epidemiological survey was performed by using all $S$. aureus from about 10 sources, such as meat animals, meat, by-products, feed, carriers, patients, and the PCR results were shown in Fig. 7.

The analysis of virulence and antibiotic resistance of S. aureus showed that 216 cultures of S. aureus among 634 Staphylococci isolates obtained from different sources throughout the agricultural production chain in this study, common gene for $S$. aureus (98.74\%), and nuс (97.48\%), тесA (44.12\%), msrA 
(9.66\%), gyrA (32.77\%) and ermC (29.41\%) genes were identified.

As seen in the surveillance result, the prevalence of
MRSA is $44 \%$ among $S$. aureus isolates. The majority of MRSA isolates (74.2\%) were from human patients in the hospitals. Coagulase positive Staphylococi account

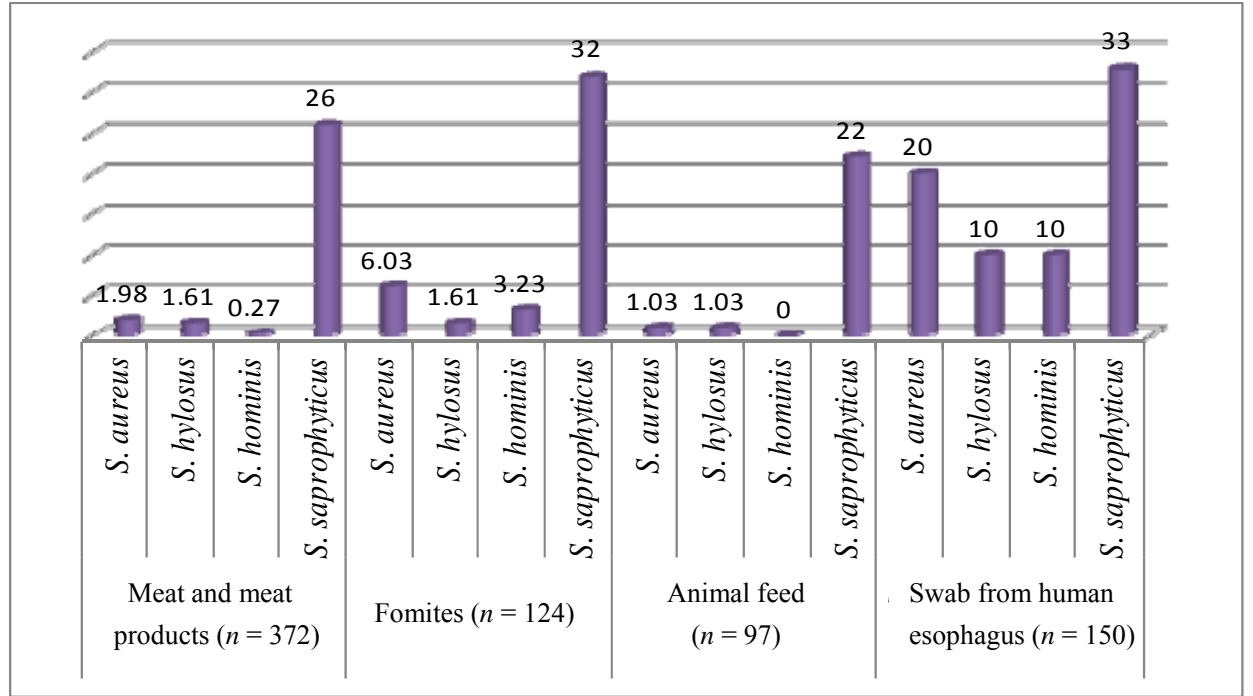

Fig. 4 Prevalence of Staphylococci serotypes.

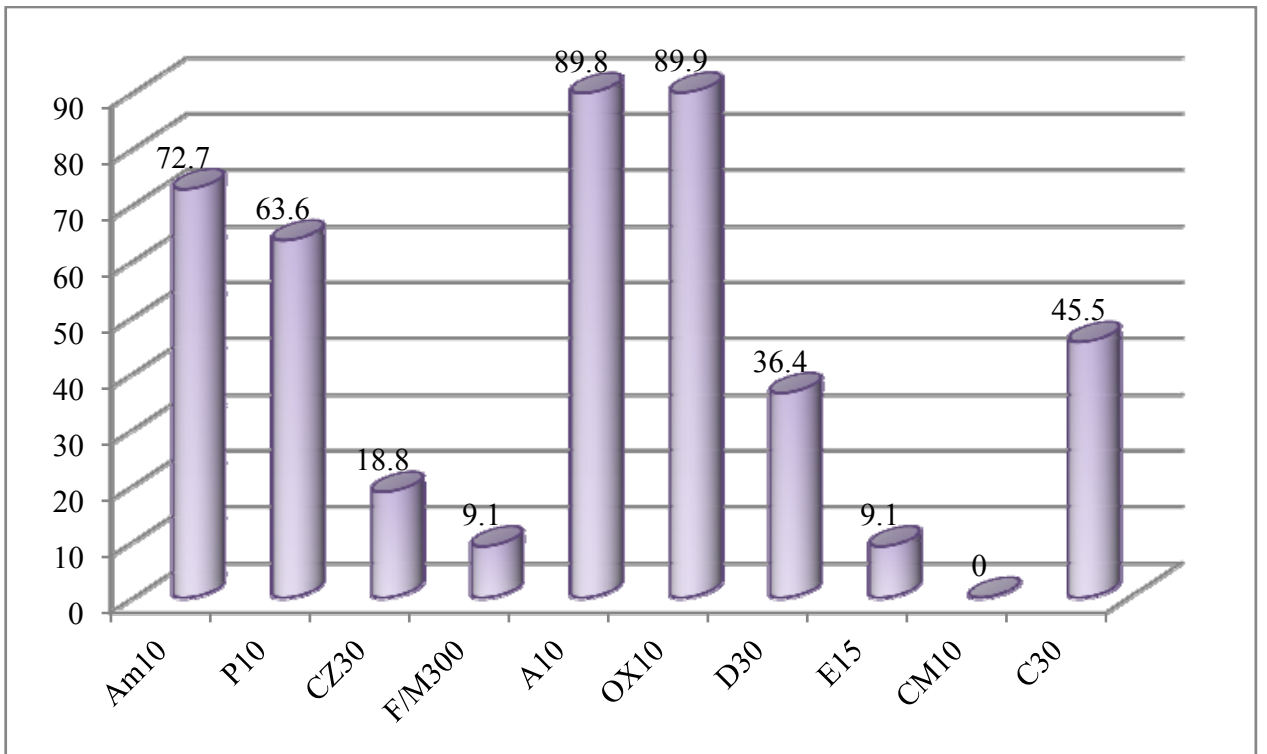

Fig. 5 Results of antibiotics testing by disk diffusion method.

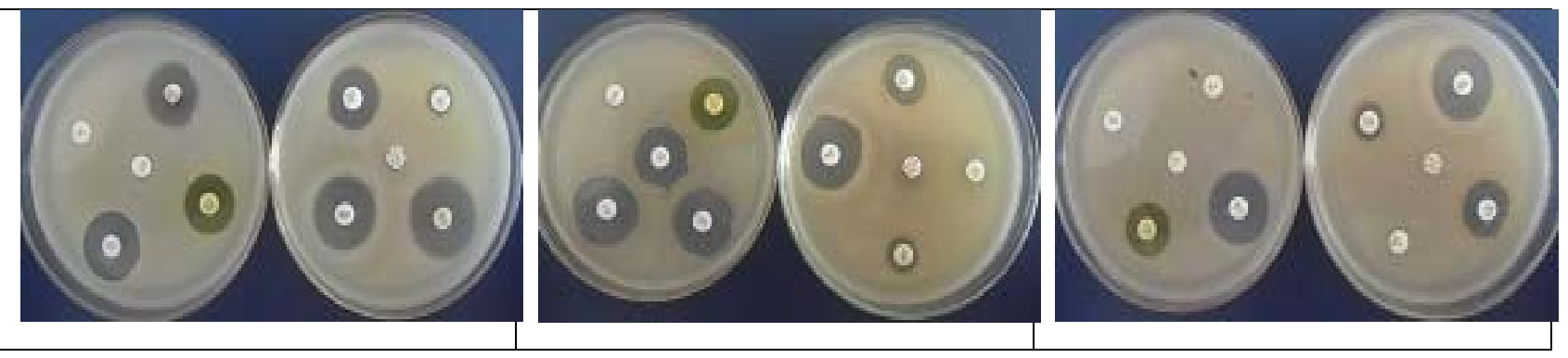

Fig. 6 Results of antibiotic resistance and susceptibility test by disk diffusion method. 


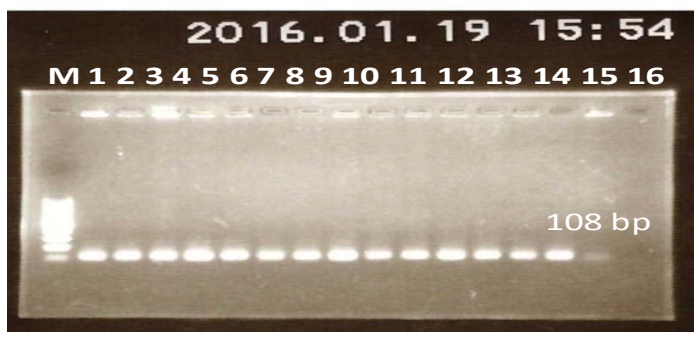

(a) PCR for common gene of $S$. aureus

Lanes M: 100 bp DNA ladder; L1: S. aureus ATCC 25923; L2-L15: samples; L16: negative control.

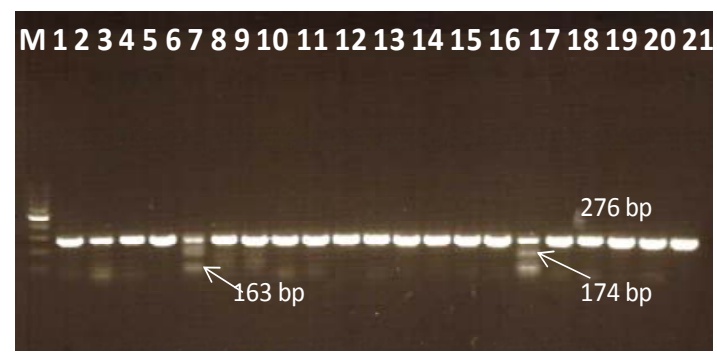

(c) Multiplex PCR for $m s r A, m e c A$ and nuc gene Lanes M: 100 bp DNA ladder;

L1-L21: samples of meat and swab of human throat swab; L7 and L17 positive for mecA and msrA.

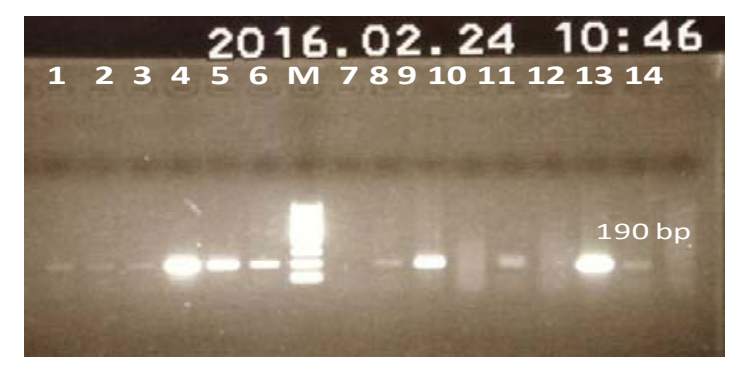

(e) PCR for ermC gene

Lanes M: 100 bp DNA ladder;

L1-L14: samples of chicken, cattle, patients.

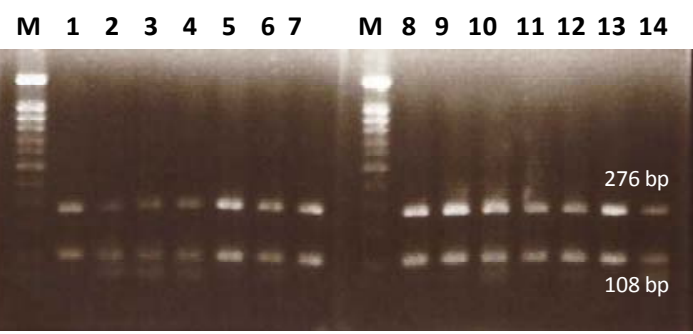

(b) Multiplex PCR for common and nuc gene Lanes M: 50 bp DNA ladder;

L1-L15: samples.

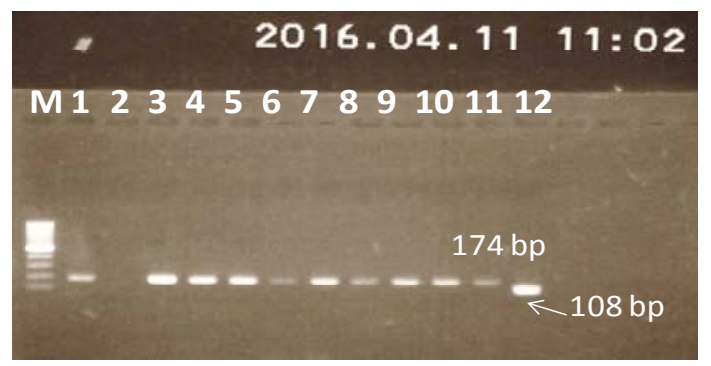

(d) Multiplex PCR for common and mecA gene Lanes M: 100 bp DNA ladder; L1: S. aureus ATCC 2921; L2: negative control; L3-L11: samples of meat and feed; L12: ATCC 25923 S. aureus (University of Hokkaido).

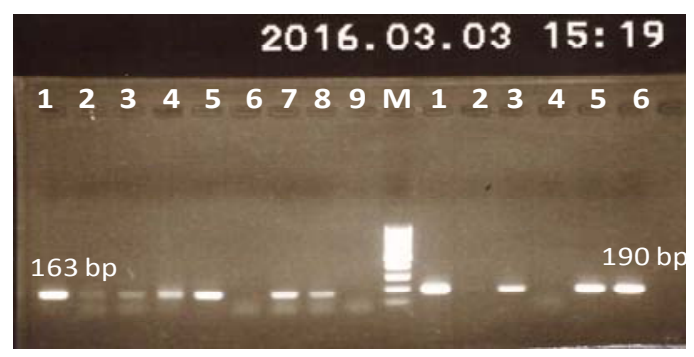

(f) PCR for msrA and ermC gene

Lanes M: 100 bp DNA ladder; Later L1-L6: samples of horse; L1-L9: samples of cattle, horse, chicken, patient, carrier and beef.

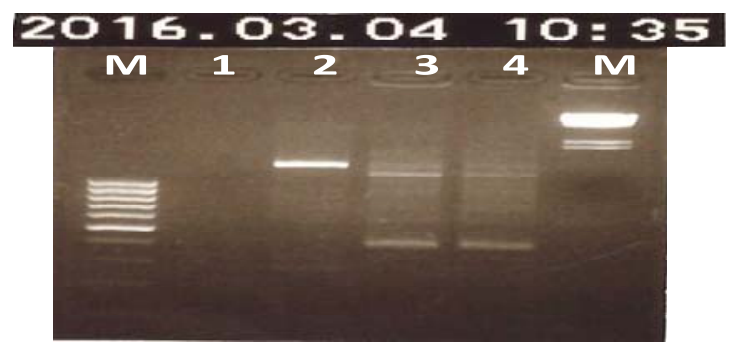

(g) PCR for gyrA gene

Lanes M: 100 bp DNA ladder; Later LM: Hind III marker

L1: S. aureus ATCC 25923; L2-L4: positive with gyrA gene.

Fig. 7 Results of PCR analysis of $S$. aureus.. 
Production Chain of Mongolia

Table 5 Results of surveillance of antibiotics resistance genes of $S$. aureus.

\begin{tabular}{lllllllll}
\hline No. & Sources & Isolates & S. aureus & mecA & msrA & gyrA & ermC & nис \\
\hline 1 & Animals & 15 & 15 & 13 & 2 & 8 & 4 & 15 \\
2 & Feed & 19 & 19 & 2 & 3 & 8 & 7 & 18 \\
3 & Meat & 38 & 38 & 16 & 5 & 9 & 12 & 38 \\
4 & Swabs & 55 & 54 & 7 & 2 & 10 & 3 & 53 \\
5 & Carrier & 3 & 3 & 1 & & 2 & & 3 \\
6 & Patients & 37 & 35 & 28 & 2 & 18 & 19 & 36 \\
7 & Sub products & 15 & 15 & 11 & 7 & 6 & 8 & 14 \\
8 & Imported chicken & 56 & 56 & 27 & 2 & 17 & 17 & 55 \\
\hline No. & & 238 & 235 & 105 & 23 & 78 & 70 & 232 \\
Percentage (\%) & 100 & 98.74 & 44.12 & 9.66 & 32.77 & 29.41 & 97.48 \\
\hline
\end{tabular}

for $10.8 \%$ of all samples, $15.9 \%$ of samples from meat production chain, and 3.6\% of horse samples (Fig. 7, Table 5). So, MRSA is the most prevalent (Table 5, Figs. 8-11). Prevalence rate was also determined. Antibiotic resistance of $S$. aureus isolates, cultures and strains, which were cultured from products and environment contaminated by $S$. aureus, was variable as shown in Figs 8-11.

The majority of cases was identified from environmental swabs and imported chickens. The high percentage of occurrence of $S$. aureus highlights the need to improve the sanitation and hygiene procedures at all levels from production to the consumption of meat.

Although there were some differences in primers used for detection of antibiotics resistance gene and antibiotics discs for some antibiotics in the study. Types of both $\beta$-lactam and non $\beta$-lactam antibiotics were consistent, and result of antibiotics disc test for oxacillin and erythromycin was also consistent with that for PCR. Results were summarized in Table 5. $\beta$-lactams are preferred antibiotics used to treat serious

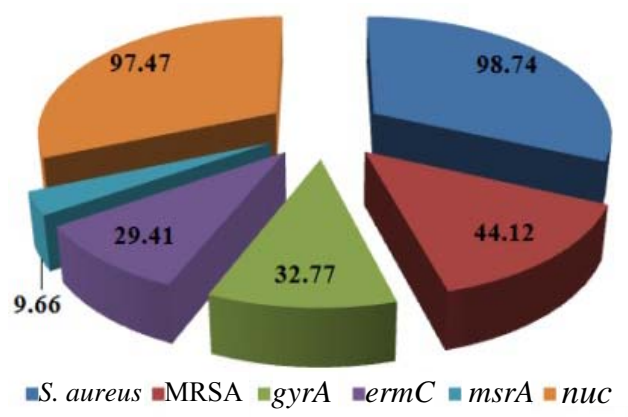

Fig. 8 Percent of virulence and antibiotic resistance genes.

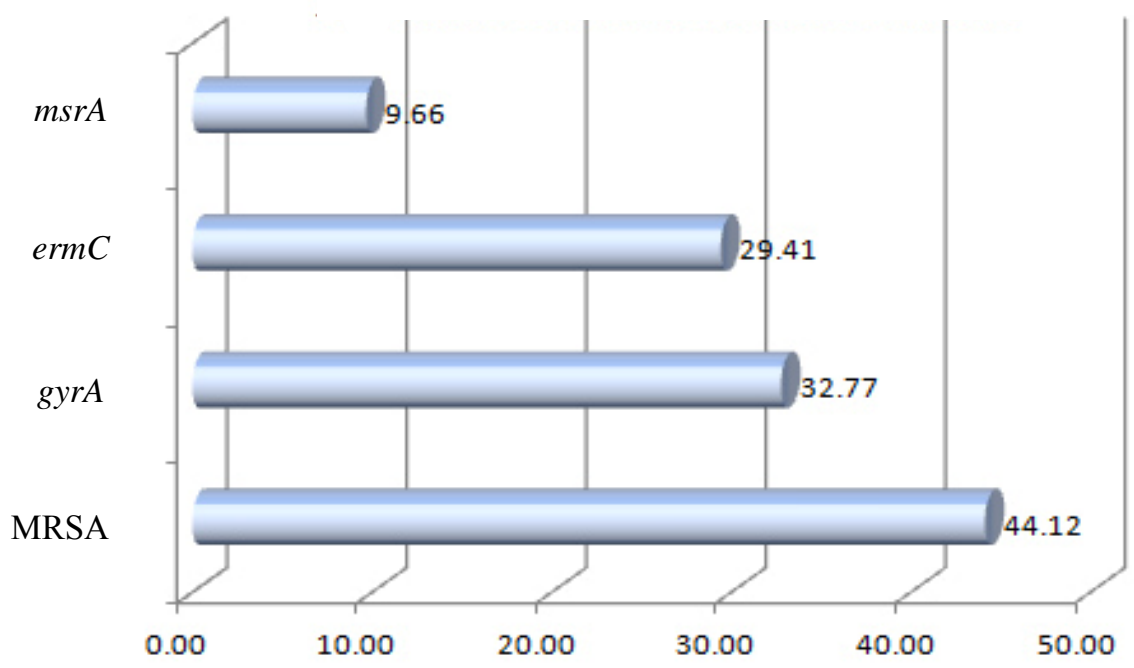

Fig. 9 Percent of antibiotic resistance S. aureus. 

Production Chain of Mongolia

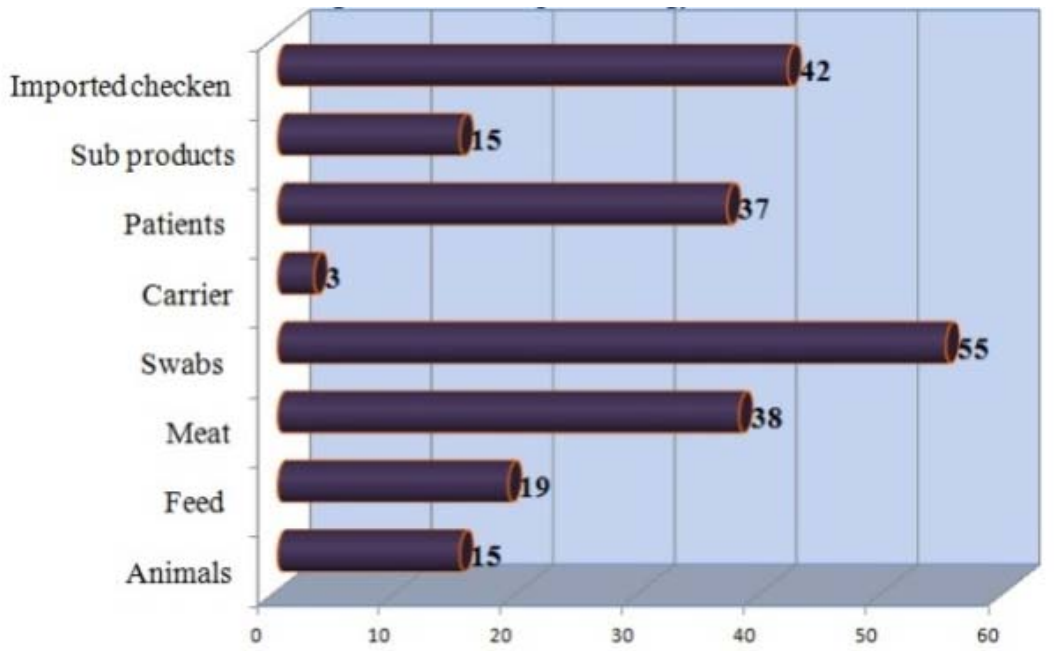

Fig. 10 The number of distribution of antibiotic resistance in $S$. aureus isolates from several sources.

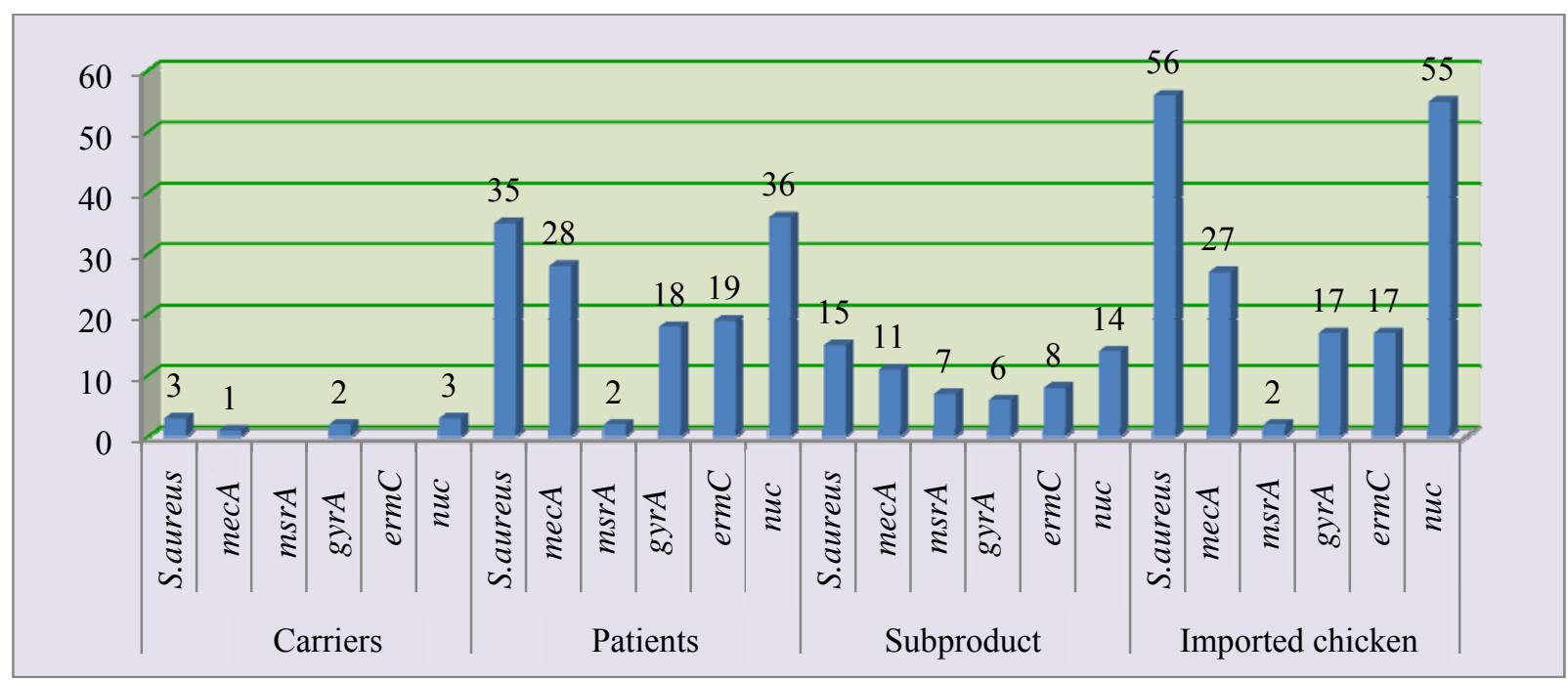

(a)

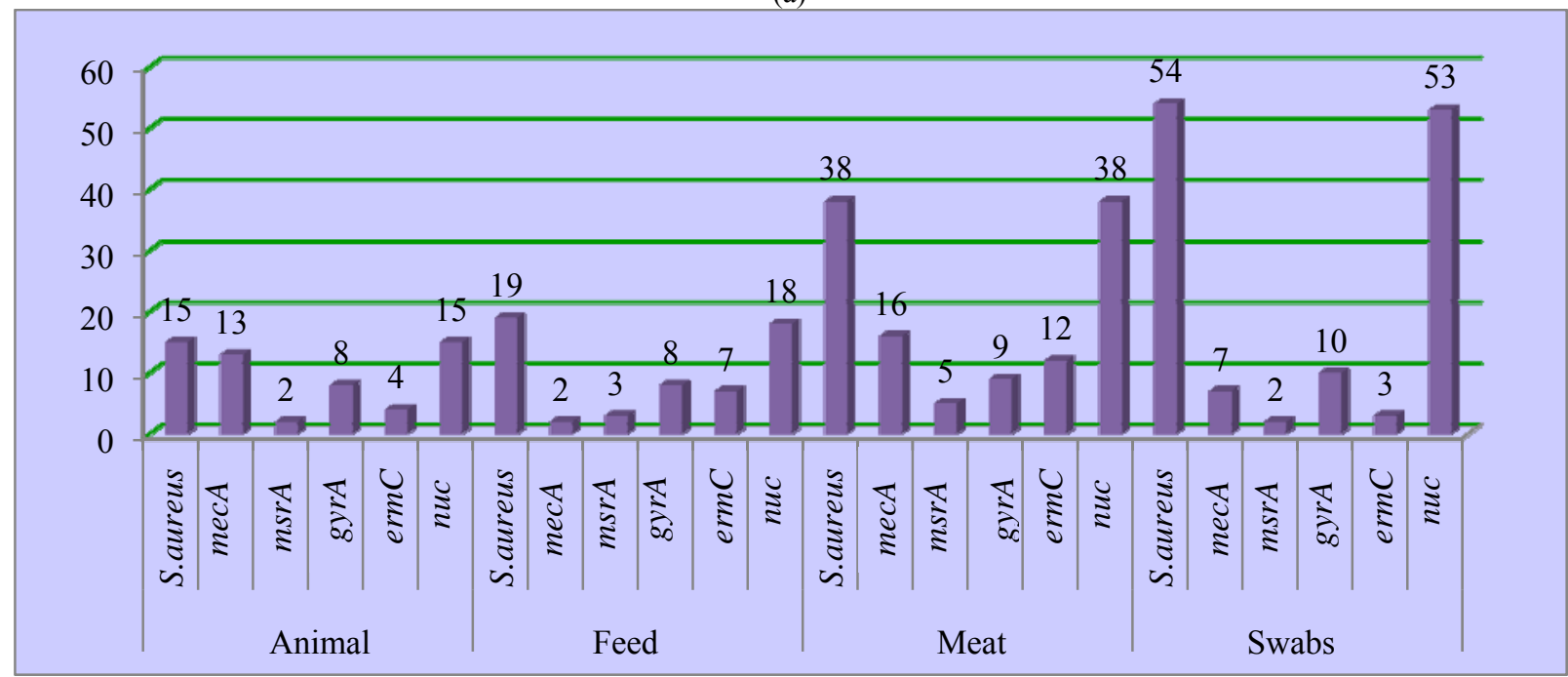

(b)

Fig. 11 The number of occurrence of antibiotic resistance among $S$. aureus. 


\section{Production Chain of Mongolia}

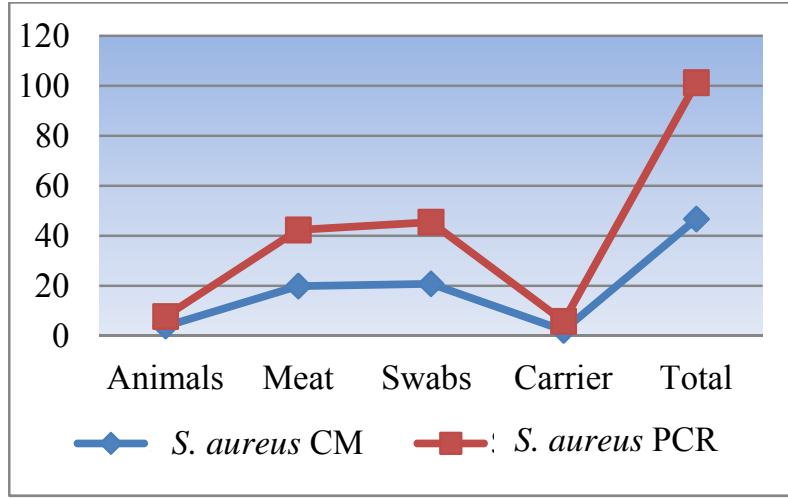

Fig. 12 Result of PCR sensitivity test.

S. aureus infections [26]. However, since 1961, when methicillin was introduced for clinical use, the occurrence of MRSA strains has steadily increased and MRSA infection have become a serious problem internationally [27, 28]. Identification of MRSA strains in food animals led to concerns regarding food-borne contamination, and MRSA has been identified in retail meat in Europe, Asia, and North America [29-31].

The prevalence of methicillin-resistance is known to more than $70 \%$ among $S$. aureus isolates from hospitals in Korea [32]. According to the present study, MRSA accounts for $44.7 \%$ of all S. aureus cultures in Mongolia. Many MRSA isolates exhibit multiple resistance to the commonly used antimicrobial agents amikacin, oxacillin, penicillin, erythromycin and tetracycline [33, 34].

\subsection{PCR Sensitivity Test Result}

The comparative study using McNemar's test showed that PCR has sensitivity of $96.2 \%$, whereas culturing method was $78.4 \%$ sensitive. There was discrepancy of $16.4 \%$ between both methods (Fig. 12) and that means microbiological analysis for processed and stored samples will be more reliable and less time-consuming if it is done at DNA level.

In the present study, direct PCR was shown to be very effective in detection of the pathogens from meat sample homogenates, indicating that it is a robust method for rapid detection in comparison with culture technique which provides a significant contribution to both regulatory agencies and meat. Especially, differences of testing results for carriers can depend on the presence of a number of issues, such as human nutrition, immunity and use of medicines, which affect bacterial viability. As well, it is observed that difference between both methods is probable to depend on the genera of bacteria.

\section{Conclusions}

Results of this surveillances of mecA positive $S$. aureus in the present study and confirmed cases of food-borne infections and intoxications caused by $S$. aureus should be considered as one of mean criteria of food safety issues in Mongolia, and special attentions should be paid on antibiotic resistant bacteria, such as S. aureus.

Due to the diversity of these resistance mechanisms and the constant appearance of new patterns, antibiotic utilization in developing countries should be under strict control and should be monitored to avoid the exhaustion of the antibiotic arsenal that is under intense use.

\section{Acknowledgments}

The authors want to acknowledge the support from the International Foundation for Science (IFS) for moral financial support.

\section{References}

[1] Lkhagvasuren S. 2015. Examination and Investigation of Veterinary and Sanitation. Ulaanbaatar, Mongolia: Munkhiin Useg Publishers, 192-5.

[2] Lkhagvasuren, S. 2007. The Polymerase Chain Reaction Technique and Diagnostic of Food Borne Infection and Intoxication. Ulaanbaatar, Mongolia: Munkhiin Useg Publishers, 113-5.

[3] Todar, K. 2016. "Todar's Online Textbook of Bacteriology." Accessed July, 2016. http://www.textbookofbacteriology.net/.

[4] Aydin, A., Sudagidan, M., and Muratoglu, K. 2011. "Prevalence of Staphylococcal Enterotoxins, Toxin Genes and Genetic-Relatedness of Food Borne S. aureus Strains Isolated in the Marmara Region of Turkey." Int. J. Food Microbiol. 148 (2): 99-106. 
[5] Lkhagvasuren, S., Gantsetseg, T., and Narantuya, A. 2013. "Survellance of Food Borne Agents of Mongolia." In Proceedings of the 6th Asian Pig Veterinary Society Congress.

[6] Chambers, H. F. 2001. "The Changing Epidemiology of Staphylococcus aureus." Emerg. Infect. Dis. 7 (2): 178-82.

[7] Casey, J. A., Curriero, F. C., Cosgrove, S. E., Nachman, K. E., and Schwartz, B. S. 2013. "High-Density Livestock Operations, Crop Field Application of Manure, and Risk of Community-Associated Methicillin-Resistant Staphylococcus aureus Infection in Pennsylvania." JAMA Intern Med. 173 (21): 1980-90.

[8] Schulz, J., Friese, A., Klees, S., Tenhagen, B. A., Fetsch, A., Rösler, U., and Hartung, J. 2012. "Longitudinal Study of the Contamination of Air and of Soil Surfaces in the Vicinity of Pig Barns by Livestock-Associated Methicillin Resistant Staphylococcus aureus." Appl. Environ. Microbiol. 78 (16): 5666-71.

[9] Eko, K. E., Forshey, B. M., Carrel, M., Schweizer, M. L., Perencevich, E. N., and Smith, T. C. 2015. "Molecular Characterization of Methicillin-Resistant Staphylococcus aureus (MRSA) Nasal Colonization and Infection Isolates in a Veterans Affairs Hospital.” Antimicrobial Resistance and Infection Control 4: 10.

[10] Gibbs, S. G., Green, C. F., Tarwater, P. M., Mota, L. C., Mena, K. D., and Scarpino, P. V. 2006. "Isolation of Antibiotic-Resistant Bacteria from the Air Plume Downwind of a Swine Confined or Concentrated Animal Feeding Operation.” Environ Health Perspect. 114 (7): 1032-7.

[11] Wendlandt, S., Schwarz, S., and Silley, P. 2013. "Methicillin-Resistant Staphylococcus aureus: A Food-Borne Pathogen." Annu. Rev. Food Sci. Technol. 4: 117-39.

[12] Enkhtuya, J. 2015. Molecular Epidemiology of Some Zoonotic Diseases and Improvement of Vaccine Technology. Report of Science Technology Project.

[13] National Center for Communicable Disease of Mongolia. “Annual Report 2013.” Accessed July, 2016. http://www.nccd.gov.mn/index.php.

[14] Xu, Y. G., Cui, L. C., Tain, C. Y., Li, S. L., Cao, J. J., Liu, Z. M., and Zhang, G. C. 2012. "A Multiplex Polymerase Chain Reaction Coupled with High Performance Liquid Chromatography Assay for Simultaneous Detection of Six Foodborne Pathogens." Food Control 25 (2): 778-83.

[15] ISO. 2003 "Enumeration of Coagulase-Positive Staphylococci (Staphylococcus aureus and Other Species)." Microbiology of Food and Animal Feeding Stuffs, ISO 6888-2:1999/Amd1:2003.

[16] Isenberg, H. D. 1992. Clinical Microbiology Procedures
Handbook. Vol. 1. Washington: American Society of Microbiology.

[17] Martineau, F., Picard, F. J., Grenier, L., Roy, P. H., Ouellette, M., and Bergeron, M. G. 2000. "Multiplex PCR Assays for the Detection of Clinically Relevant Antibiotic Resistance Genes in Staphylococci Isolated from Patients Infected after Cardiac Surgery: The ESPRIT Trial." J. Antimicrob. Chemother. 46 (4): 527-34.

[18] Projan, S. J., Monod, M., Narayanan, C. S., and Dubnau, D. 1987. "Replication Properties of pIM13, a Naturally Occurring Plasmid Found in Bacillus subtilis, and of Its Close Relative pE5, a Plasmid Native to Staphylococcus aureus.” J. Bacteriol. 169 (11): 5131-9.

[19] Ryffel, C., Bucher, R., Kayser, F. H., and Berger-Bachi, B. 1991. "The Staphylococcus aureus mec Determinant Comprises an Unusual Cluster of Direct Repeats and Codes for a Gene Product Similar to the Escherichia coli sn-Glycerophosphoryl Diester Phosphodiesterase." $J$. Bacteriol. 173 (23): 7416-22.

[20] Ross, J. I., Eady, E. A., Cove, J. H., Cunliffe, W. J., Baumberg, S., and Wootton, J. C. 1990. "Inducible Erythromycin Resistance in Staphylococci Is Encoded by a Member of the ATP-Binding Transport Super-Gene Family." Mol. Microbiol. 4 (7): 1207-14.

[21] Brakstad, O. G., Aasbakk, K., and Maeland, J. A. 1992. "Detection of Staphylococcus aureus by Polymerase Chain Reaction Amplication of the nuc Gene." Journal of Clinical Microbiology 30 (7): 1654-60.

[22] Killgore, G. E., Halloway, B., and Tenover, F. C. 2000. “A 5' Nuclease PCR (Taq Man) High-Throughput Assay for Detection of the mecA Gene in Staphylococci." Journal of Clinical Microbiology 38 (7): 2516-9.

[23] Jorgensen, J. H., and Ferraro, M. J. 2009. "Antimicrobial Susceptibility Testing: A Review of General Principles and Contemporary Practices." Clin. Infect. Dis. 49 (11): 1749-55.

[24] Owuna, G., Abimiku, R. H., Nkene, I. H., Joseph, G. W., and Ijalana, O. O. 2015. "Isolation and Antibiotic Susceptibility of Staphylococcus aureus from Fresh Poultry Meat Sold in Keffi Metropolis, Nigeria." International Journal of Research Studies in Biosciences 3 (11): $1-5$.

[25] Martineau, F., Picard, F. J., Lansac, N., Ménard, C., Roy, P. H., Ouellette, M., and Bergeron, M. G. 2000. "Correlation between the Resistance Genotype Determined by Multiplex PCR Assays and the Antibiotic Susceptibity Patterns of Staphylococcus aureus and Staphylococcus epidermidis." Antimicrob. Agents Chemother. 44 (2): 231-8.

[26] Bauer, K. A., West, J. E., Balada-Llasat, J. M., Pancholi, P., Stevenson, K. B., and Goff, D. A. 2010. "An 


\section{Production Chain of Mongolia}

Antimicrobial Stewardship Program's Impact with Rapid Polymerase Chain Reaction Methicillin-Resistant Staphylococcus aureus Blood Culture Test in Patients with S. aureus Bacteremia." Clin. Infect. Dis. 51 (9): 1074-80.

[27] Zecconi, A., Calvinho, L., and Fox, L. 2006. "Staphylococcus aureus Intramammary Infections." Bulletin of the International Dairy Federation, Brussels, Belgium. Accessed July 2016. https://www.livivo.de/doc/B2243729.

[28] Neder, V. E., Canavesio, V. R., and Calvinho, L. F. 2011. "Presence of Enterotoxigenic Staphylococcus aureus in Bulk Tank Milk from Argentine Dairy Farms." Rev. Argent. Microbiol. 43 (2): 104-6.

[29] Miranda, J. M., Mondragon, A., Vazquez, B. I., Fente, C. A., Cepeda, A., and Franco, C. M. 2009. "Influence of Farming Methods on Microbiological Contamination and Prevalence of Resistance to Antimicrobial Drugs in Isolates from Beef." Meat Science 82 (2): 284-8.

[30] Adesiji, Y. O., Alli, O. T., Adekanle, M. A., and Jolayemi, J. B. 2011. "Prevalence of Arcobacter, Escherichia coli, Staphylococcus aureus and Salmonella Species in Retail
Raw Chicken, Pork, Beef and Goat Meat in Osogbo, Nigeria." Sierra Leone J. Biomed. 3 (1): 8-12.

[31] Lim, S. K., Nam, H. M., Park, H. J., Lee, H. S., Choi, M. J., Jung, S. C., Lee, J. Y., Kim, Y. C., Song, S. W., and Wee, S. H. 2010. "Prevalence and Characterization of Methicillin-Resistant Staphylococcus aureus in Raw Meat in Korea." Journal of Microbiol. Biotechnol. 20 (4): 775-8.

[32] Kim, E. S., Song, J. S., Lee, H. J., Choe, P. G., Park, K. H., Cho, J. H., Park, W. B., Kim, S. H., Bang, J. H., Kim, D. M., Park, K. U., Shin, S., Lee, M. S., Choi, H. J., Kim, N. J., Kim, E. C., Oh, M. D., Kim, H. B., and Choe, K. W. 2007. "A Survey of Community-Associated Methicillin-Resistant Staphylococcus aureus in Korea." J. Antimicrob. Chemother. 60 (5): 1108-14.

[33] Khanna, T., Freindship, R., Dewey, C., and Weese, J. S. 2008. "Methicillin Resistant Staphylococcus aureus Colonization in Pigs and Pig Farmers." Vet. Microbiol. 128 (3-4): 298-303.

[34] Smith, T. C., and Pearson, N. 2011. "The Emergence of Staphylococcus aureus ST398." Vector-Borne Zoonot. Dis. 11 (4): 327-39. 